\title{
Adsorption Dynamics of Ecofriendly Litter Wastes For Zn(II)/Cr(VI) From Electroplating Effluents - Continuous Column Method
}

\author{
N Muthulakshmi Andal' ${ }^{1}$, S Charulatha ${ }^{2}$, J Anuradha ${ }^{2}$ and Gayathri NS ${ }^{2}$ \\ ${ }^{1}$ Assistant Professor, Department of Chemistry, PSGR Krishnammal College for Women, Coimbatore. \\ ${ }^{2}$ Research Scholar, Department of Chemistry, PSGR Krishnammal College for Women, Coimbatore.
}

Received: September 18, 2016; Accepted: October 05, 2016; Published: October 20, 2016

*Corresponding author: N Muthulakshmi Andal, Assistant Professor, Department of Chemistry, PSGR Krishnammal College for Women, Coimbatore-4, Email:muthulakshmiandal@psgrkc.com

\begin{abstract}
Electroplating industries, play a momentous role in the development and growth of numerous metal manufacturing, but also equally pollute the environment through various means. Most of the electroplating industries operated in Coimbatore are reported under Red category list, their main source of pollution being heavy metal leaching into aquatic streams. The present work deals with the sorption of $\mathrm{Zn}(\mathrm{II})$ and $\mathrm{Cr}(\mathrm{VI})$ being highly prevalent electroplating effluents. The process of biosorption has many attractive features compared to the conventional effluent treatment methods adopted so for. Batch studies are conducted at varying operating factors to assess the best sorption efficiency amongst the chosen cost effective and eco-friendly materials viz., Mussel Shell Powder (MSP), Prosopis juliflora Bark (PJB), Terminallia cattapa Seed Shell (TCSS) and Aegle marmelos correa (AMC). Based on the experimental data the Treated Mussel Shell Powder (TMSP) and Treated Prosopis juliflora Bark (TPJB) are found to be the best sorbent for $\mathrm{Zn}(\mathrm{II})$ and $\mathrm{Cr}(\mathrm{VI})$ removal respectively. The scaling up process through column experiments are performed to quantify the efficiency of the fixed sorbents under optimized conditions. The long term analysis at the laboratory levels, reveal $100 \%$ and $92 \%$ metal removal for $\mathrm{Zn}(\mathrm{II})$-TMSP and $\mathrm{Cr}(\mathrm{VI})$ TPJB systems respectively.
\end{abstract}

Keywords: Electroplating; Effluent; Biosorbents; Column; Coimbatore

\section{Introduction}

Industrial sectors expansion involves increased usage of non-biodegradable heavy metals and leading of excess toxic pollutants through liquid effluents. This is an issue of growing concern for humanity and its ecosystem. The wastewaters emanating from such industries viz., plating, tanning, metallurgy require treatment before discharging, but least cared, wherein heavy metal ions like $\mathrm{Cr}(\mathrm{VI})$ and $\mathrm{Zn}(\mathrm{II})$ are present.

The tolerance limit for $\mathrm{Cr}(\mathrm{VI})$ and $\mathrm{Zn}(\mathrm{II})$ ions from the effluent discharges into surface waters are $0.1 \mathrm{mg} / \mathrm{L}$ and 5.0 $\mathrm{mg} / \mathrm{L}$ respectively. In potable water, it is $0.05 \mathrm{mg} / \mathrm{L}$ and 10.0 $\mathrm{mg} / \mathrm{L}$ correspondingly [1]. The health risks of $\mathrm{Cr}(\mathrm{VI})$ and $\mathrm{Zn}(\mathrm{II})$ ions while exceeding the permissible limits results in skin allergy, liver, stomach problems and also found to be carcinogenic [2]. It is essential to sequestrate these ions from polluted areas, suggesting suitable methodology.

Various methodologies such as electrochemical, ion exchange, membrane filtration, evaporation, solvent extraction, emulsion per traction technology, reverse osmosis and chemical coagulation, are available for trapping of heavy metal ions. But these methods possess their own disadvantages, often involving high capital/operational costs and generation of secondary wastes $[3,4]$.

Biosorption process is one of the efficient methods in trapping toxic metal ions, due to its simplicity, sludge-free operation, easiness in handling, availability of various adsorbents and also efficient removal of heavy metals at lower-concentration levels itself [5]. Biosorbents are prepared from natural waste biomasses that are available in large quantities or certain waste collected from agricultural operations. These low/ no cost materials are reported to have excellent sorption potential that are affordable and eco-friendly.

The current study evaluates the biosorption capacity of litter wastes in trapping $\mathrm{Cr}(\mathrm{VI})$ and $\mathrm{Zn}(\mathrm{II})$ ions via batch / column method. MSP, PJB, TCSS and AMC were identified, prepared, treated before experimental verification. Removal of heavy metal ions employing the above said eco-friendly materials have not been reported elsewhere in literature.

\section{Materials and Methods \\ Collection/Treatment of adsorbent materials}

The identified litter waste materials Mussell Shell (MSP), Prosopis juliflora Bark (PJB), Terminallia cattapa Seed Shell (TCSS) and Aeglemarmeloscorrea (AMC) (Figure 1) were collected from localities of Coimbatore, Kangeyam, Salem and coastal areas of Tamil Nadu. Collected PJB, MSP and AMC were washed, sun dried, crushed down into small pieces and then sieved. The sieved particles of different mesh sizes for the four materials were treated with $0.1 \mathrm{~N} \mathrm{HCl}$ for 3 hours, washed several 


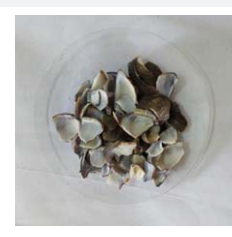

MSP

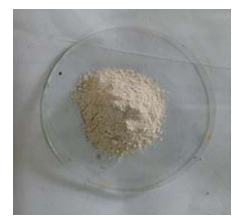

TMSP
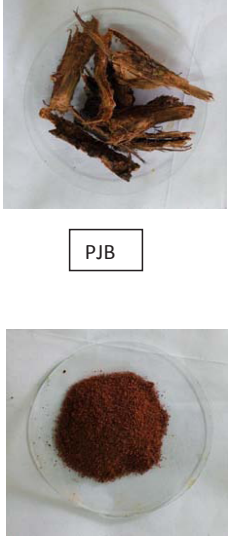

TPJB

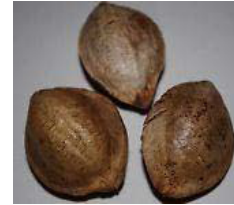

TCSS

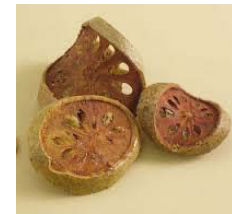

AMC

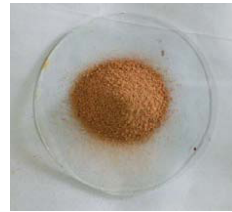

TTCSS

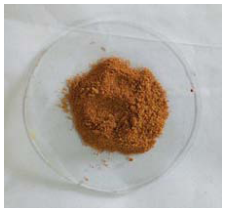

TAMC

Figure 1: Raw and treated adsorbent materials.

times to neutralize and then air dried. The several washings during neutralization procedure ensure the increase in surface area while soaking the materials. The acid treated Mussell Shell powder (TMSP), Prosopisjuliflora Bark (TPJB), Terminallia cattapa Seed Shell (TTCSS) and Aegle marmeloscorrea (TAMC) were stored in air tight containers.

\section{Chemicals}

All the chemicals employed were of Analytical Reagent grade. Doubly Distilled (DD) water was used for preparation and dilutions of solutions. A stock of $1000 \mathrm{ppm}$ metal solutions was prepared by dissolving required amount of $\mathrm{K}_{2} \mathrm{Cr}_{2} \mathrm{O}_{7}$ and $\mathrm{Zn}\left(\mathrm{NO}_{3}\right)_{2}$ in $1000 \mathrm{ml}$ of standard flask. The $\mathrm{pH}$ of the solutions were adjusted using $0.1 \mathrm{~N} \mathrm{HCl}$ and $0.1 \mathrm{~N} \mathrm{NaOH}$.

\section{Batch equilibration studies}

The equilibration of $\mathrm{Cr}(\mathrm{VI})$ and $\mathrm{Zn}(\mathrm{II})$ aqueous solutions ( $50 \mathrm{ml}$ volume) with the materials were experimentally verified in a mechanical shaker (KEMI) to define the role of variable parameters viz., particle sizes $(0.18 \mathrm{~mm}, 0.24 \mathrm{~mm}, 0.30 \mathrm{~mm}$, $0.42 \mathrm{~mm}$ and $0.52 \mathrm{~mm}$ ) and dosages $(200 \mathrm{mg}, 400 \mathrm{mg}, 500 \mathrm{mg}$, $1 \mathrm{~g}, 2 \mathrm{~g}$ ) of the treated adsorbents, initial concentrations of the aqueous $\mathrm{Cr}(\mathrm{VI})$ and $\mathrm{Zn}(\mathrm{II})$ solutions $(100-1000 \mathrm{mg} / \mathrm{L}: 100 \mathrm{mg} / \mathrm{L}$ interval), preset time intervals between the sorbent and sorbate species (10-120 minutes : 30 minutes interval), $\mathrm{pH}$ of the medium $(2,4,7,9$ and 11$)$ and temperature (293K-333K : $10 \mathrm{~K}$ interval) in order to assess the sorption efficiencies under laboratory conditions. The agitated samples were filtered and the residual metal ion (Cr(VI) and Zn(II)) concentrations were analyzed using Atomic Absorption Spectrophotometer: Shimadzu (AA 6200) (Figure 2) as per standard methods.

All experiments were carried out in duplicate and mean values are presented with the maximum deviation of $2.0 \%$. The percentage removal and amount adsorbed were determined as follows:
Removal percentage $(\%)=\left(\mathrm{C}_{1}-\mathrm{C}_{2}\right) / \mathrm{C}_{1} \mathrm{X} 100$

Amount adsorbed $(\mathrm{mg} / \mathrm{g})=\left(\mathrm{C}_{1}-\mathrm{C}_{2}\right) \mathrm{XV} / \mathrm{M}$

where,

$\mathrm{C}_{1}=$ initial metal concentration $(\mathrm{mg} / \mathrm{L}), \mathrm{C}_{2}=$ final metal concentration $(\mathrm{mg} / \mathrm{L}), \mathrm{V}=$ volume $(\mathrm{ml})$ and $\mathrm{M}=$ mass of adsorbent (mg).

\section{Results and Discussion}

\section{Effect of Particle Size}

Tables 1(a)-1(b) show the influence of variable particle sizes of the sorbent materials on the varying systems indicating $0.18 \mathrm{~mm}$ size to be the favorable size for maximum removal. This is owed to the surface phenomenon, smaller adsorbent size offers larger surface area for metal binding.

\section{Effect of Contact Time/Initial Concentration}

The effect of contact time at varying time intervals and that of initial concentrations for the systems are listed in tables 2(a) and 2(b), wherein the registered data indicate the enhancement in amount adsorbed only up to certain metal ion concentrations. This may be of the saturation in the sorption sites on the sorbent as the concentration of the metal ions increased. The varying time intervals for the systems indicate the attainment of equilibrium up to specific contact time, further increase in time interval registered a decline.

\section{Effect of Dosage}

The amounts of metal ion adsorbed at different dosages are listed in tables 3(a) \& 3(b). The maximum sorptive ability of the materials under varying conditions depict their potentiality as able adsorbents in sequestering heavy metal ions.

\section{Effect of pH}

Maximum uptake was observed at $\mathrm{pH} 2.5$ for $\mathrm{Cr}(\mathrm{VI})$. At increasing $\mathrm{pH}$ environments, a sharp decline in uptake was 
observed, which is in good agreement with previous reports. The speciation studies of $\mathrm{Cr}(\mathrm{VI})$ in aqueous solution shows that $\mathrm{H}_{2} \mathrm{CrO}_{4}$ predominates at $\mathrm{pH}$ less than $1.0, \mathrm{HCrO}_{4}^{-}$for $\mathrm{pH}$ between 1.0 and 6.0 and $\mathrm{CrO}_{4}{ }^{2-}$ at $\mathrm{pH}$ above 6 . This is due to the electrostatic attraction between the positively charged surfaces of the adsorbent with $\mathrm{HCrO}_{4}^{-}$ions. But in highly acidic medium ( $\left.\mathrm{pH}=1.0\right)$, $\mathrm{H}_{2} \mathrm{CrO}_{4}$ (neutral form) is the predominant species of $\mathrm{Cr}(\mathrm{VI})$. Hence, percentage removal decreased due to the involvement of less number of $\mathrm{HCrO}_{4}^{-}$anions to the positive surface. At higher $\mathrm{pH}$ value, the reduction in adsorption may be due to the dual competition of both $\mathrm{OH}^{-}$and $\mathrm{CrO}_{4}{ }^{2-}$ ions to get adsorbed on the surface of the adsorbent among which $\mathrm{OH}^{-}$predominates. These results are in agreement with several previous investigations on metal removal by a variety of materials.

The $\mathrm{pH}$ dependence for $\mathrm{Zn}(\mathrm{II})$ systems registered maximum removal between 5-7; the other ranges exhibit irregular curves. The reason being that at low acidic medium, the $\mathrm{H}^{+}$ions compete with the metal ions to get sorbed on the materials and under higher basic conditions metal ions combine with $\mathrm{OH}^{-}$ions to form respective precipitates.

The optimized conditions resulted from the batch studies for the chosen materials are, $\mathrm{Cr}(\mathrm{VI})$ system: $0.18 \mathrm{~mm}, 200 \mathrm{mg}$, $1000 \mathrm{ppm}, 60 \mathrm{~min}, \mathrm{pH} 2.5,30^{\circ} \mathrm{C}$; Zn(II) system: $0.18 \mathrm{~mm}, 1.5 \mathrm{~g}$,

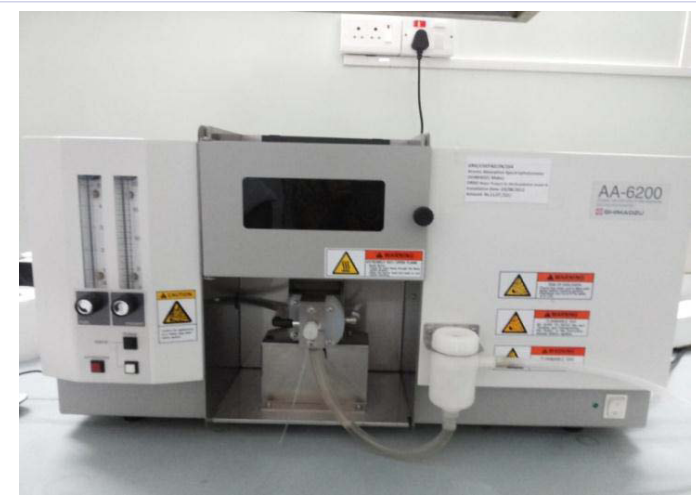

Figure 2: Atomic Absorption Spectrophotometer Shimadzu (AA 6200).

Table 1(a): Cr (VI)-Particle Size.

\begin{tabular}{|l|l|l|l|l|l|}
\hline \multirow{2}{*}{ Adsorbents } & \multicolumn{5}{|c|}{ Amount Adsorbed (mg/g) } \\
\cline { 2 - 6 } & $\mathbf{0 . 1 8} \mathbf{~ m m}$ & $\mathbf{0 . 2 4} \mathbf{~ m m}$ & $\mathbf{0 . 3 0} \mathbf{~ m m}$ & $\mathbf{0 . 4 2} \mathbf{~ m m}$ & $\mathbf{0 . 7 1} \mathbf{~ m m}$ \\
\hline TTCSS & 16.8854 & 4.335 & 4.3340 & 4.542 & 4.452 \\
\hline TPJB & 22.6303 & 6.876 & 5.93834 & 5.826 & 5.8337 \\
\hline TMSP & 13.1202 & 7.85 & 6.9756 & 6.7262 & 4.3826 \\
\hline TAMC & 11.3931 & 9.384 & 6.837 & 6.383 & 5.3836 \\
\hline
\end{tabular}

Table 1(b): Zn(II)-Particle Size.

\begin{tabular}{|l|l|l|l|l|}
\hline \multirow{2}{*}{ Adsorbents } & \multicolumn{4}{|l|}{ Amount Adsorbed (mg/g) } \\
\cline { 2 - 5 } & $\mathbf{0 . 1 8} \mathbf{~ m m}$ & $\mathbf{0 . 2 4} \mathbf{~ m m}$ & $\mathbf{0 . 3 0} \mathbf{~ m m}$ & $\mathbf{0 . 4 2} \mathbf{~ m m}$ \\
\hline TTCSS & 38.23 & 28.21 & 19.74 & 22.23 \\
\hline TPJB & 55.43 & 44.43 & 33.17 & 27.72 \\
\hline TMSP & 83.76 & 25.52 & 22.29 & 19.32 \\
\hline TAMC & 41.87 & 34.32 & 27.28 & 28.38 \\
\hline
\end{tabular}

\begin{tabular}{|c|c|c|c|c|c|c|}
\hline \multirow{2}{*}{ Adsorbents } & \multirow{2}{*}{$\begin{array}{l}\text { Time } \\
\text { (min) }\end{array}$} & \multicolumn{5}{|c|}{ Amount Adsorbed (mg/g) } \\
\hline & & 100 ppm & 250ppm & 500ppm & 750ppm & 1000 ppm \\
\hline \multirow{3}{*}{ TTCSS } & 30 & 2.7165 & 3.827 & 5.726 & 6.837 & 5.342 \\
\hline & 60 & 3.9482 & 5.9147 & 9.2536 & 10.5213 & 16.8854 \\
\hline & 120 & 2.9726 & 3.98216 & 6.726 & 8.8726 & 10.765 \\
\hline \multirow{3}{*}{ TPJB } & 30 & 3.726 & 4.7236 & 7.837 & 10.872 & 6.865 \\
\hline & 60 & 4.1617 & 9.9872 & 15.009 & 17.921 & 22.6303 \\
\hline & 120 & 3.5262 & 5.837 & 14.763 & 12.2726 & 7.976 \\
\hline \multirow{3}{*}{ TMSP } & 30 & 0.564 & 1.987 & 4.676 & 4.765 & 6.876 \\
\hline & 60 & 1.2867 & 3.4775 & 8.5776 & 9.6274 & 13.1202 \\
\hline & 120 & 0.9875 & 2.234 & 6.765 & 6.9765 & 10.976 \\
\hline \multirow{3}{*}{ TAMC } & 30 & 0.9876 & 1.234 & 3.654 & 4.876 & 7.9876 \\
\hline & 60 & 2.4485 & 2.9872 & 7.1107 & 7.5983 & 11.3931 \\
\hline & 120 & 1.2343 & 1.7654 & 4.7656 & 5.764 & 8.654 \\
\hline
\end{tabular}

Table 3(a): Cr (VI)-Dosage.

\begin{tabular}{|l|l|l|l|l|l|}
\hline \multirow{2}{*}{ Adsorbents } & \multicolumn{5}{|l}{ Amount Adsorbed (mg/g) } \\
\cline { 2 - 6 } & $\mathbf{2 0 0} \mathbf{~ m g}$ & $\mathbf{3 0 0} \mathbf{~ m g}$ & $\mathbf{4 0 0} \mathbf{~ m g}$ & $\mathbf{5 0 0} \mathbf{~ m g}$ & $\mathbf{1 0 0 0} \mathbf{~ m g}$ \\
\hline TTCSS & 16.8854 & 11.625 & 10.298 & 9.937 & 8.282 \\
\hline TPJB & 22.6303 & 17.2726 & 15.765 & 11.7598 & 10.282 \\
\hline TMSP & 7.282 & 8.2822 & 9.765 & 11.272 & 13.1202 \\
\hline TAMC & 11.3931 & 9.2826 & 8.875 & 5.3837 & 5.3837 \\
\hline
\end{tabular}

Table 3(b): Zn (II)-Dosage.

\begin{tabular}{|l|l|l|l|l|l|}
\hline \multirow{2}{*}{ Adsorbent } & \multicolumn{5}{ll}{ Amount adsorbed (mg/g) } \\
\cline { 2 - 6 } & $100 \mathrm{mg}$ & $200 \mathrm{mg}$ & $300 \mathrm{mg}$ & $500 \mathrm{mg}$ & $1000 \mathrm{mg}$ \\
\hline TTCS & 24.85 & 26.87 & 29.76 & 31.87 & 38.23 \\
\hline TPJB & 11.23 & 29.87 & 31.98 & 37.45 & 55.43 \\
\hline TMSP & 38.65 & 46.87 & 52.87 & 61.87 & 83.76 \\
\hline TAMC & 26.85 & 33.76 & 34.98 & 39.87 & 41.87 \\
\hline
\end{tabular}

$750 \mathrm{ppm}, 60 \mathrm{~min}, \mathrm{pH} 5.6,30^{\circ} \mathrm{C}$. Further increase in agitation time, beyond the attainment of equilibrium, registered least changes in the residual concentrations of the metal ions. The most suitable adsorbent for maximum removal of $\mathrm{Cr}(\mathrm{VI})$ is observed to be TPJB, since it is a natural bio accumulator of $\mathrm{Cr}(\mathrm{VI})$ by the transaction of metal to the aerial part of the plant [5]. It is an active transport mechanism and the preferential order being TPJB > TTCSS > TMSP>TAMC. TMSP is found to be best for Zn(II) system, for the reason that the TMSP is more porous in nature when compared to other adsorbents and the preferential order being TMSP $>$ TPJB $>$ TTCSS $>$ TAMC.

\section{Column Studies}

The Batch mode studies are the basic pilot studies performed to screen the biosorbents before adopting the adsorption method to the field levels. The results of the Batch equilibration method insist the feasibility and compatibility of the chosen systems for their promising application. Based on batch studies results, column studies were carried out to quantify the adsorbents' efficiencies in the continuous columns' running with the aqueous 
$\mathrm{Cr}(\mathrm{VI})$ and $\mathrm{Zn}(\mathrm{II})$ solutions with TPJB and TMSP respectively [6]. Later, the column schemes are extended to the effluent discharges.

\section{Column packing}

The column is made up of cylindrical glass tube, the inner diameter is $2.5 \mathrm{~cm}$ and the height is $30 \mathrm{~cm}$. It was packed with sorbent materials between two supporting layers of glass wool spread with the glass beads at the top of the already packed glass wool layer placed at the bottom. The step by step packing is as: Glass wool layer ( $3 \mathrm{~cm}$ thickness), glass beads (2cm thickness), TPJB /TMSP (50/300 g: $6 \mathrm{~cm}$ height), glass wool (1 $\mathrm{cm}$ thickness). These materials were loaded from the top of the column and allowed to settle by gravity force. The bottom of the column was fitted with rubber with flow adjustable knob and thus the outflow rate was controlled by adjusting the knob (Figure 5).

$1000 \mathrm{mg} / \mathrm{L}$ aqueous solutions of $\mathrm{Cr}(\mathrm{VI})$ and $\mathrm{Zn}(\mathrm{II})$ were prepared and poured from the top of columns slowly and the flow rate through the columns were fixed as $100 \mathrm{ml} / 5 \mathrm{mins}$ for $\mathrm{Cr}(\mathrm{VI})$-TPJB system and $100 \mathrm{ml} / 20$ seconds for $\mathrm{Zn}(\mathrm{II})-\mathrm{TMSP}$ system after several trials. Maximum removal of $98 \%$ and $100 \%$ were registered for $\mathrm{Cr}(\mathrm{VI})$-TPJB \& $\mathrm{Zn}(\mathrm{II})$-TMSP respectively, after analysis in AAS. The percentage removal was observed to decline upto $90 \%$ after passing 20 litres of inlet solutions. Further decline was envisaged upto 30 litres and then the column went exhausted.

\section{Collection of Effluent Samples}

Wastewaters containing $\mathrm{Cr}(\mathrm{VI})$ and $\mathrm{Zn}(\mathrm{II})$ ions above the tolerance levels were found at various electroplating industries located in Kurumbapalayam region of Coimbatore. 10 litres of these effluent samples were collected in pre cleaned PET bottles of 1 litre capacity and analyzed for $\mathrm{Cr}(\mathrm{VI})$ and $\mathrm{Zn}(\mathrm{II})$ ions of initial concentrations (AAS) after a series of dilutions, $\mathrm{Cr}(\mathrm{VI})$ : $720 \mathrm{mg} / \mathrm{L}, \mathrm{Zn}(\mathrm{II}): 40 \mathrm{mg} / \mathrm{L}$. The $\mathrm{pH}$ and conductivity values of the samples were also recorded using LABTRONICS pH meter and conductivity meter respectively (Table 4). Zinc plating bath the processing, uncoated/ Zn plated materials and the effluents generated are represented in figure 4.

\section{Analysis of Industrial Effluents- Batch/Column Methods}

Effluent concentrations of $50 \mathrm{mg} / \mathrm{L}$ were fixed for the batch

Table 4: Effluent Samples - Initial Concentrations

\begin{tabular}{|c|c|c|c|c|c|}
\hline S. No & $\begin{array}{c}\text { Name of } \\
\text { Industries }\end{array}$ & $\begin{array}{c}\mathbf{C r}(\mathbf{V I}) \\
\mathbf{( m g / L )}\end{array}$ & $\begin{array}{c}\mathbf{Z n ( I I )} \\
\mathbf{( m g} / \mathbf{L})\end{array}$ & $\begin{array}{c}\text { Conductivity } \\
\mathbf{( m v )}\end{array}$ & $\mathbf{p H}$ \\
\hline 1 & Unit I & 71.52 & 25.87 & 21.76 & 2.3 \\
\hline 2 & Unit II & 695.75 & 3.398 & 32.98 & 1.98 \\
\hline 3 & Unit III & 211 & 2.817 & 29.82 & 2.98 \\
\hline 4 & Unit IV & 6.4647 & 23.298 & 87.87 & 5.35 \\
\hline 5 & Unit V & 5.875 & 5.876 & 90.79 & 0.57 \\
\hline 6 & Unit VI & 449.6 & 4.383 & 24.4 & 1.82 \\
\hline 7 & Unit VII & 720.05 & 40.08 & -0.693 & 3.45 \\
\hline
\end{tabular}

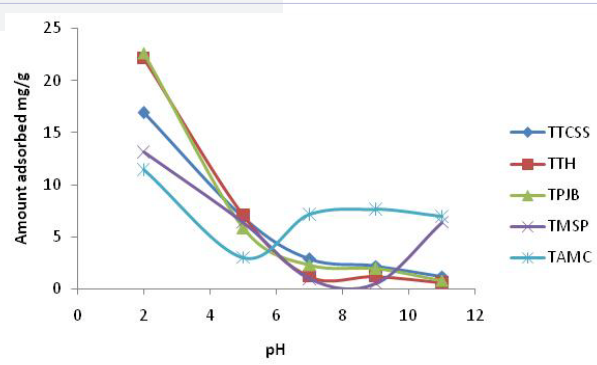

Figure 3a: Effect of $\mathrm{pH}-\mathrm{Cr}(\mathrm{VI}$.

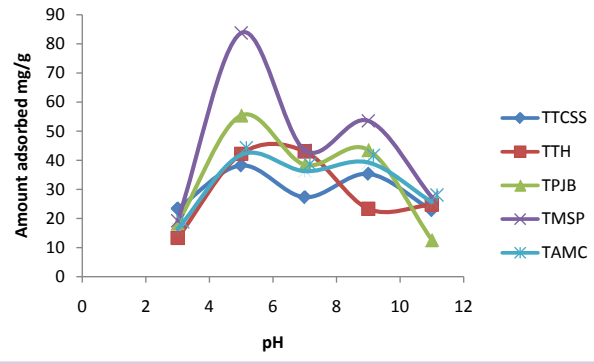

Figure 3b: Effect of $\mathrm{pH}$ - $\mathrm{Zn}(\mathrm{II})$.

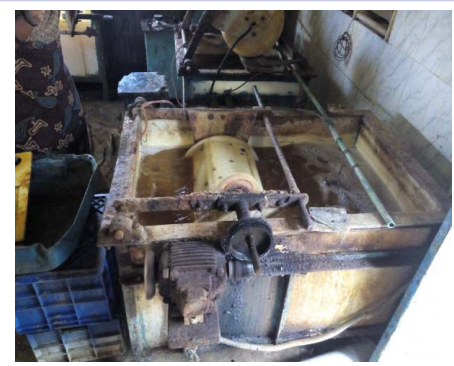

Figure 4a: Zinc Plating bath.

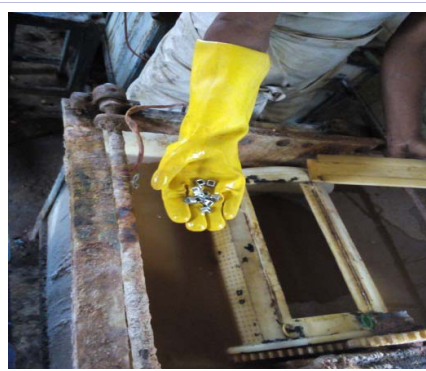

Figure 4b: Work at the bath plating.

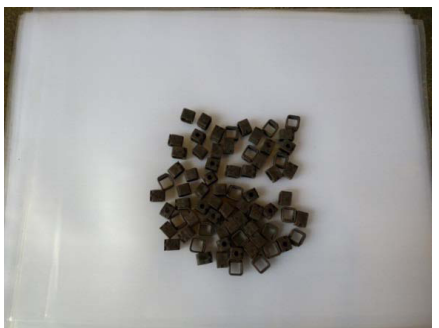

Figure 4c: Material before platting 


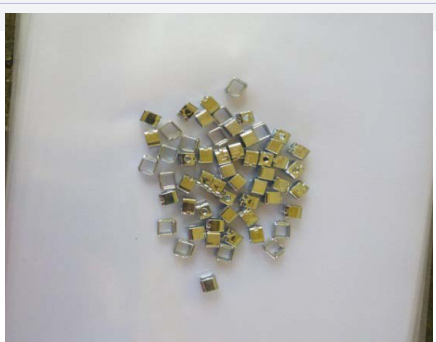

Figure 4d: Material after platting

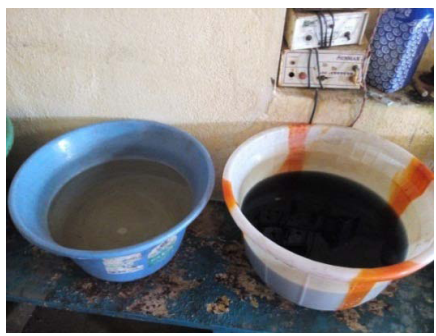

Figure 4e: Effluent generated from the bath.
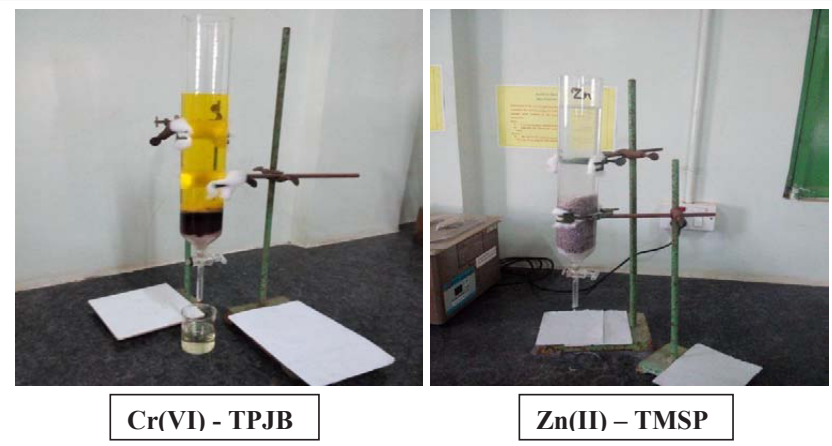

Figure 5: Column packing.

studies and experimentally verified (TPJB and TMSP) under the optimized conditions. The results revealed an appreciable $70 \%$ removal of $\mathrm{Cr}(\mathrm{VI})$ and $\mathrm{Zn}(\mathrm{II})$ ions under batch mode.

sorptive nature of the sorbent materials was quantitatively estimated by the performance of the column studies, on the basis of the long term analysis at the laboratory conditions. The values recorded are $100 \%$ and $92 \%$ for $\mathrm{Zn}(\mathrm{II})$ and $\mathrm{Cr}(\mathrm{VI})$ ions respectively.

\section{Conclusion}

Batch equilibration method was adopted to analysis the effect of the variables viz., particle sizes and dosages of the adsorbents (TTCSS, TPJB, TMSP, TAMC), initial concentrations of the adsorbate solutions ( $\mathrm{Zn}(\mathrm{II}), \mathrm{Cr}(\mathrm{VI})$ ), predetermined time intervals between the sorbent - sorbates materials, $\mathrm{pH}$ of the solution media and temperatures. TPJB and TMSP were derived to be the best sorbents amongst all the identified materials based on the optimized conditions through batch equilibrium studies. Quantification of these results was justified by column method for the aqueous metal solutions with the fixed sorbent materials. Various electroplating industries located in and around Coimbatore were identified and surveyed for the extent of metal pollution. The effluent samples containing $40 \mathrm{mg} / \mathrm{L}$ of $\mathrm{Zn}(\mathrm{II})$ and $720 \mathrm{mg} / \mathrm{L}$ of $\mathrm{Cr}(\mathrm{VI})$ were collected from Electroplating Industries at Kurumbapalayam area and the performance of the column for these effluent discharges revealed $100 \%$ and $92 \%$ removal for $\mathrm{Zn}(\mathrm{II})$ and $\mathrm{Cr}(\mathrm{VI})$ ions respectively. The concluding remarks holds good for TPJB and TMSP to be promising litter waste materials in the sequestrating $\mathrm{Cr}(\mathrm{VI})$ and $\mathrm{Zn}(\mathrm{II})$ ions at field levels.

\section{Financial Support}

The authors submit their due acknowledgment to Defence Research \& Development Organization (DRDO), New Delhi for the timely Financial Support in execution of the research work

\section{References}

1. EPA: Environmental pollution control alternatives: EPA/625/590/25, EPA/625/4-89/023 Environmental Protection Agency: Cincinaati: Ohio: USA. 1990.

2. Owlad M, Aroua MK, Daud WAW and Baroutian S. Removal of hexavalent chromium-contaminated water and wastewater: a review. Water, Air, and Soil Pollution. 2009;200(1):59-77.

3. Volesky B. Detoxification of metal-bearing effluents: biosorption for the next century. Hydrometallurgy. 2001;59(2-3):203-216. Doi: doi. org/10.1016/S0304-386X(00)00160-2

4. Wilde EW, Benemann JR, Wilde EW and Benemann JR. Bio removal of heavy metals by the use of microalgae. Biotechnol Adv. 1993;11(4):781-812.

5. Monser L and Adhoum N. Modified activated carbon for the removal of copper, zinc, chromium and cyanide from waste water. Separation and Purification Technology. 2002;26(2-3):137-146.

6. Sugashini S and Meera Sheriffa Begum KM. Column Adsorption Studies for the Removal of $\operatorname{Cr}(\mathrm{VI})$ Ions by Ethylamine Modified Chitosan Carbonized Rice Husk Composite Beads with Modeling and Optimization. J of Chem. 2013;2013:pp.11. Doi: doi. org/10.1155/2013/460971 